\title{
Sarcomatoid Renal Cell Carcinoma With Unusual Metastasis to the Small Intestine Manifesting as Perforated Appendicitis
}

\author{
XIAOYAN LIAO*, SOHAIB H. ABU-FARSAKH* and DONGWEI ZHANG \\ Department of Pathology and Laboratory Medicine, University of Rochester Medical Center, Rochester, NY, U.S.A.
}

\begin{abstract}
Background: Sarcomatoid renal cell carcinoma is a rare form of dedifferentiated carcinoma with a high metastatic rate and adverse prognosis. Common sites of metastasis include lymph nodes, lung, liver and bone. We report a case of sarcomatoid renal cell carcinoma with unusual metastasis to the small intestine in a 65-year-old female with a history of clear-cell renal cell carcinoma with focal sarcomatoid transformation. Case Report: The patient presented to the Emergency Department with worsening abdominal pain. Imaging showed perforated acute appendicitis, however, diagnostic laparoscopy found no evidence of appendicitis, but a small punctate perforation in the small intestine. Gross examination of the small intestine showed a $2 \mathrm{~cm}$ tan-white lobular firm lesion at the perforation site involving the full thickness of the wall. Histological examination revealed a high-grade spindle-cell neoplasm with hyperchromatic and pleomorphic nuclei, frequent mitotic figures, and necrosis. Immunohistochemically, the tumor cells were positive for $\mathrm{CD} 10$ and carbonic anhydrase 9, but negative for pan-cytokeratin, epithelial membrane antigen, paired box gene 8, renal cell carcinoma, desmin, smoothmuscle actin, $c-K I T$, discovered on gastrointestinal stromal tumor protein 1, CD34, and S100. Molecular studies showed that the tumor cells were microsatellite stable but harbored mutations in polybromo-1, telomerase reverse transcriptase, and von Hippel-Lindau genes, supporting renal cell carcinoma in nature. The patient received radiation therapy but unfortunately died after one month due to rapid disease progression. Conclusion: This was a rare and challenging
\end{abstract}

This article is freely accessible online.

*These Authors contributed equally to this work.

Correspondence to: Dongwei Zhang, MD, Ph.D., Department of Pathology and Laboratory Medicine, University of Rochester Medical Center, Rochester, NY, U.S.A. Tel: +1 5852765653, Fax: +1 5852733637, dongwei_zhang@urmc.rochester.edu

Key Words: Sarcomatoid renal cell carcinoma, metastasis, perforated appendicitis. case of sarcomatoid renal cell carcinoma metastasis to the small intestine with loss of some renal cell carcinoma markers, reinforcing the aggressive nature of this entity and the importance of correlating findings with the prior history for reaching correct diagnosis.

Sarcomatoid renal cell carcinoma ( $\mathrm{RCC}$ ) is a rare form of dedifferentiated renal cell carcinoma (RCC) with aggressive clinical behavior (1-3). Metastasis can be seen in up to $70 \%$ of patients with sRCC and is associated with poor overall survival (4-6). Common sites of metastasis include lymph nodes, lung, liver and bone (7-10). In this report, we describe a case of sRCC with unusual metastasis to the small intestine in a 65-year-old female for whom the initial clinical impression was perforated appendicitis.

\section{Case Report}

A 65-year-old female with history of clear-cell RCC status post left radical nephrectomy a year and half earlier, presented to the Emergency Department with abdominal pain that worsened acutely with migration to the right lower quadrant. Appendicitis was clinically suspected and computerized tomographic scan performed on the same day was consistent with perforated acute appendicitis. The patient was taken to the operating room 5 days later. During surgery, no evidence of appendicitis was noted but a small punctate perforation of the small intestine was seen, the etiology of which was unknown, and segmental small intestine resection was performed.

On gross examination, the wall of the small intestine was thickened and a $0.4 \mathrm{~cm}$ transmural defect was identified. Upon sectioning, a $2 \mathrm{~cm}$ tan-white lobular lesion was noted invading through the entire wall. Microscopically, the appendix showed fibrous obliteration and acute serositis, but no acute appendicitis was noted. Sections from the lesion showed a high-grade malignant neoplasm composed of spindle cells. The tumor cells were hyperchromatic and pleomorphic, with frequent mitotic figures and patchy necrosis. Immunohistochemically, the tumor cells were diffusely and strongly positive for CD10 and carbonic 
anhydrase 9 (CA IX), but negative for pan-cytokeratin, epithelial membrane antigen (EMA), paired box gene 8 (PAX8), desmin, smooth-muscle actin, c-KIT, discovered on gastrointestinal stromal tumor protein 1 (DOG1), CD34, and S100 (Figure 1).

The patient's previous nephrectomy specimen was reviewed. The patient had pT3aN1 clear-cell RCC with focal sarcomatoid features involving $5 \%$ of the tumor. Interestingly, immunohistochemical staining showed that the clear-cell component was positive for pan-cytokeratin while the sarcomatoid component had lost cytokeratin expression. Both components were positive for CD10 (Figure 2). Compared to the sarcomatoid component of the primary tumor, the tumor cells involving the small intestine were similar in morphology, but showed more cytological atypia and mitotic figures. Molecular studies were performed and showed that the metastatic tumor cells harbored mutations in polybromo-1 (PBRM1) (splice site $3616+1 \mathrm{G}>\mathrm{T})$, telomerase reverse transcriptase $(T E R T)$ (promoter $-124 \mathrm{C}>\mathrm{T}$ ), and von HippelLindau (VHL) (R161) genes. Overall, the histological and immunohistochemical features in this specimen along with the patient's clinical history were consistent with metastatic sRCC.

Shortly after the surgery, the patient underwent re-staging computerized tomographic scans and was found to have lung, liver, and bone metastases. The patient received radiation therapy but unfortunately died after 1 month due to the rapid progression of metastatic disease.

\section{Discussion}

sRCC is a highly aggressive variant of RCC. About $3 \%$ of RCCs are purely sarcomatoid; however, sarcomatoid dedifferentiation can be found in any subtype of RCC and is associated with poor prognosis. The sarcomatoid component can be fibrous, leiomyomatous, rhabdoid, osteoid, or chondroid. The pattern and degree of pleomorphism do not affect clinical behavior, and all sRCCs are considered to be International Society of Urological Pathology grade 4 because of their poor prognosis (11). The most common treatment strategy for sRCC is radical nephrectomy followed by chemotherapy and immunotherapy $(4,12,13)$. The presence of distant metastases at the radical nephrectomy and histologicaI tumor necrosis are significantly associated with death from patients with sRCC (3).

The immunohistochemical staining pattern in sRCC can be variable. In one study of 42 cases, $80 \%$ of sRCC cases showed immunostaining for at least one epithelial marker, such as pan-cytokeratin, cytokeratin 7 , cytokeratin 18 , and EMA, and the expression rates for CA IX, CD10, and PAX8 were $76 \%, 76 \%$, and $64 \%$, respectively (14). In our case, the tumor metastatic to the small intestine was positive for CD10 and CA IX but did not express the epithelial markers pancytokeratin and EMA.
The molecular characterization of metastatic tumors of sRCC has not been extensively studied due to the rarity of this tumor type. The advanced nature and rapid progression of disease have further limited the number of patient samples available for analysis. Somatic mutations in $P B R M 1$ are discovered in nearly half of all clear-cell RCCs (15). PBRM1 gene mutation in clear-cell RCC is correlated with late tumor stage and poor patient prognosis (16). TERT promoter mutations were detected in 9\% (9/96) of clear-cell RCCs and $13 \%(1 / 8)$ of chromophobe RCCs, with mutations correlating with advanced grade, metastasis, and higher TERT expression (17). VHL mutations and inactivation of the $V H L$ promoter have been reported to occur frequently in clear-cell RCC (18). One study reported VHL mutation in $3 \%(1 / 35)$ of sRCC (19). VHL mutations were associated with high tumor stage and worse clinical outcomes (20). In our case, the molecular studies showed that the tumor harbored mutations in PBRM1, TERT and VHL genes, suggesting that this is a very aggressive disease with poor prognosis. Despite radiation therapy, the patient soon died due to rapid disease progression.

In summary, we describe a very rare and challenging case of sRCC metastatic to the small intestine in which the primary tumor had only a small sarcomatoid component (5\%) that was immunophenotypically different from the rest of the tumor but still expressed some of the common RCC markers. This case demonstrates the importance of investigating correlation with the previous history of the patient and the use of multiple immunohistochemical markers when necessary in reaching the correct diagnosis in unusual cases. The molecular study results may help develop potential treatment strategies by targeting molecules in those gene pathways in sRCC.

\section{Conflicts of Interest}

None.

\section{Authors' Contributions}

X.L., S.A, and D.Z. contributed to the design and implementation of the study, to the analysis of the results and to the writing of the article.

\section{References}

1 Peralta-Venturina MD, Moch $\mathrm{H}$, Amin M, Tamboli P, Hailemariam S and Mihatsch M: Sarcomatoid differentiation in renal cell carcinoma: A study of 101 cases. Am J Surg Pathol 25: 275-284, 2001. PMID: 11224597. DOI: 10.1097/00000478200103000-00001

2 Abrahams NA, Ayala AG and Czerniak B: Chromophobe renal cell carcinoma with sarcomatoid transformation. Ann Diagn Pathol 7: 296-299, 2003. PMID: 14571432. 

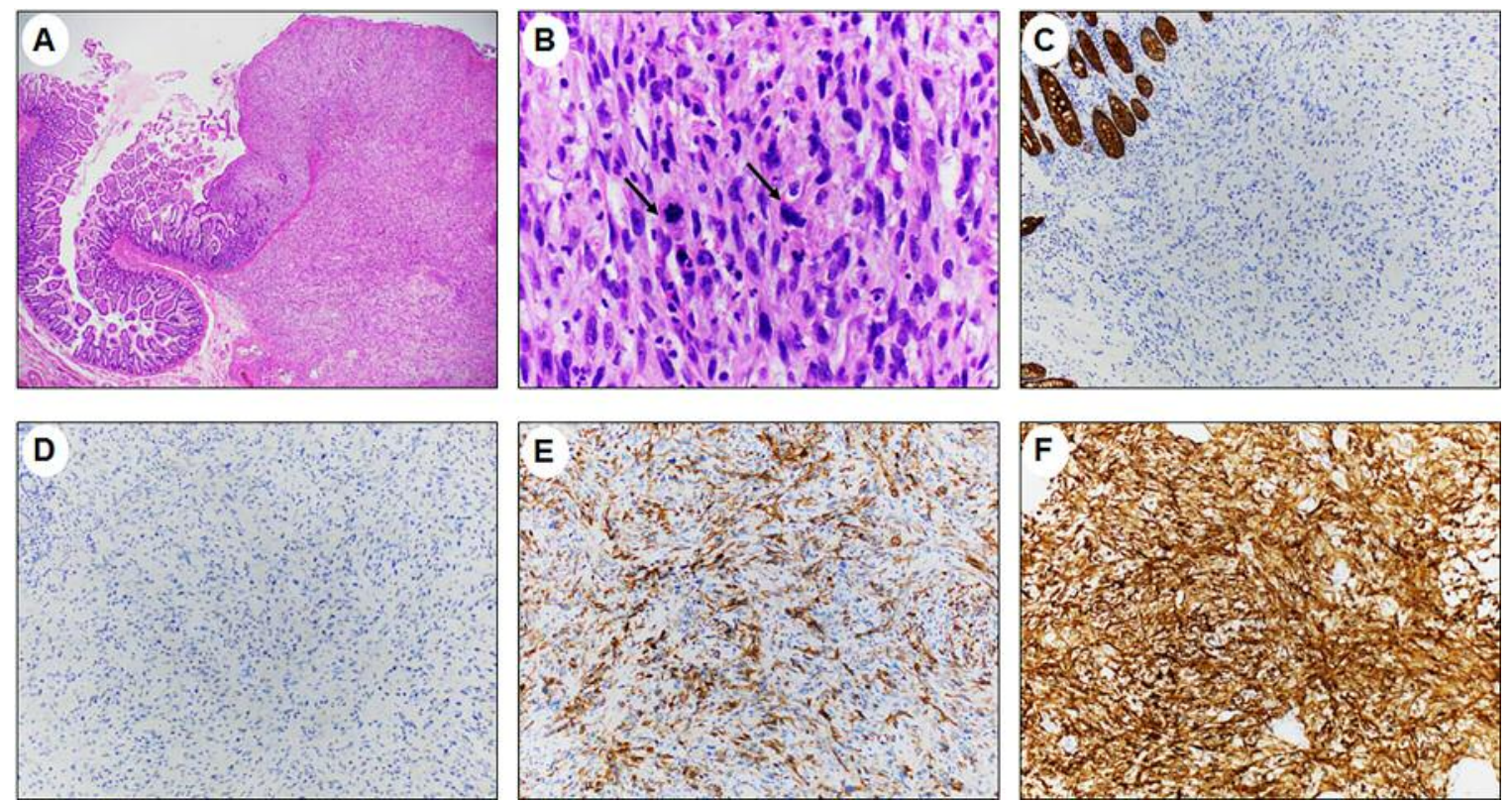

Figure 1. Histological features and ancillary studies of the metastatic sarcomatoid renal cell carcinoma found in the small intestine of our patient. A: Low-power view of the tumor showing a high-grade spindle cell/sarcomatoid neoplasm infiltrating the small intestine (hematoxylin and eosin, magnification: $\times 20$ ). B: High-power view showing sarcomatoid tumor cells with hyperchromatic and pleomorphic nuclei, and frequent mitotic figures (arrows) (hematoxylin and eosin, $\times 400)$. Immunohistochemically, the tumor cells were negative for pan-cytokeratin $(C)$ and paired box gene $8(D)$, and positive for carbonic anhydrase $9(E)$ and CD10 $(F)(\times 100)$.
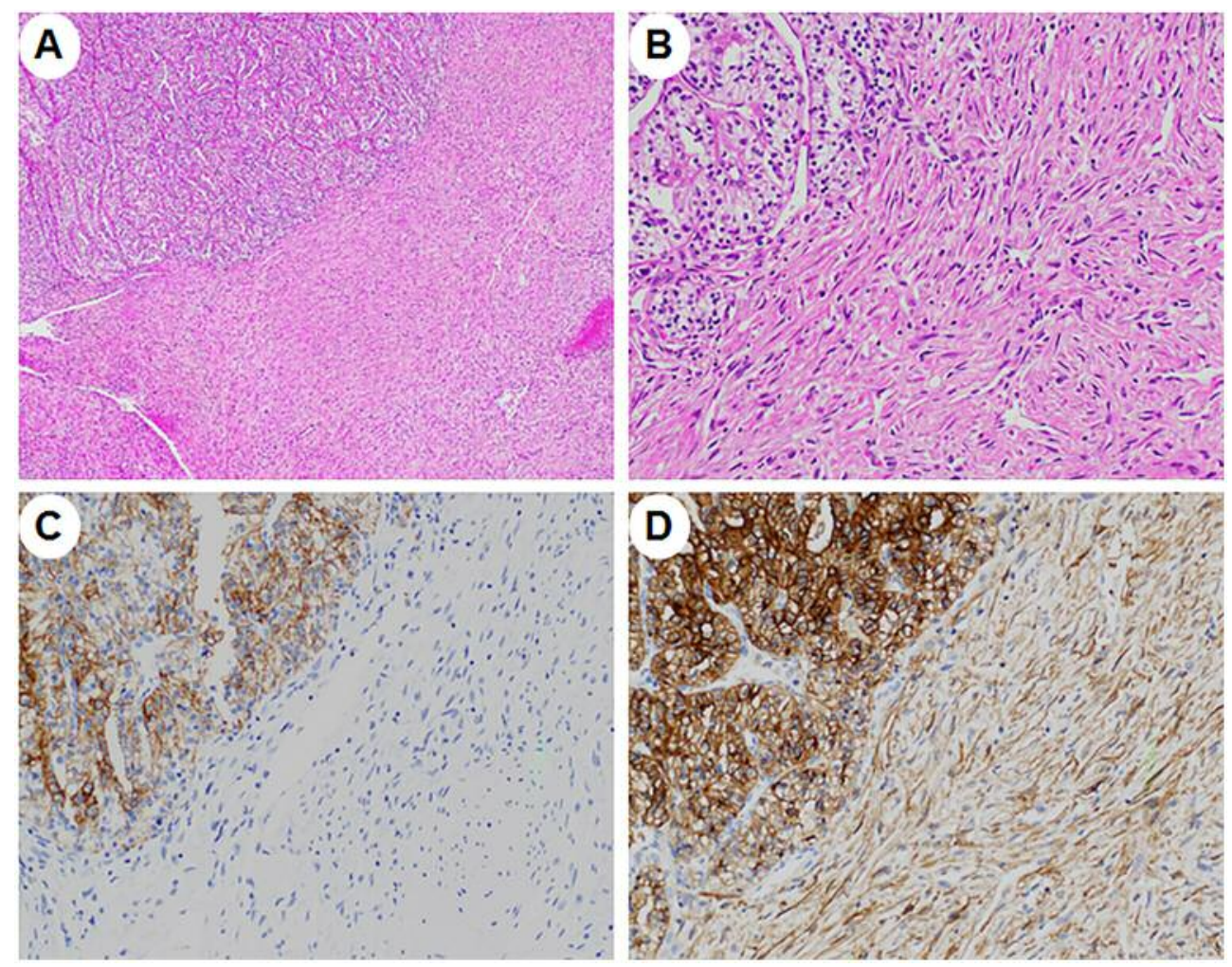

Figure 2. Histological features and ancillary studies of the primary renal cell carcinoma. A and B: The kidney tumor showing clear-cell component (upper left) and spindle/sarcomatoid component (lower right) (magnification: A, x40; B, x100). C: Pan-cytokeratin was positive in the clear-cell component but negative in the sarcomatoid component $(\times 200)$. D: Both clear-cell and sarcomatoid components were positive for CD10 $(\times 200)$. 
3 Cheville JC, Lohse CM, Zincke H, Weaver AL, Leibovich BC, Frank I and Blute ML: Sarcomatoid Renal Cell Carcinoma: An examination of underlying histologic subtype and an analysis of associations with patient outcome. Am J Surg Pathol 28: 435441, 2004. PMID: 15087662. DOI: 10.1097/00000478200404000-00002

4 Mian BM, Bhadkamkar N, Slaton JW, Pisters PW, Daliani D, Swanson DA and Pisters LL: Prognostic factors and survival of patients with sarcomatoid renal cell carcinoma. J Urol 167: 6570, 2002. PMID: 11743277.

5 Shuch B, Bratslavsky G, Linehan WM and Srinivasan R: Sarcomatoid renal cell carcinoma: a comprehensive review of the biology and current treatment strategies. Oncologist 17: 4654, 2012. PMID: 22234634. DOI: 10.1634/theoncologist.20110227

6 Adibi M, Thomas AZ, Borregales LD, Merrill MM, Slack RS, Chen HC, Sircar K, Murugan P, Tamboli P, Jonasch E, Tannir NM, Matin SF, Wood CG and Karam JA: Percentage of sarcomatoid component as a prognostic indicator for survival in renal cell carcinoma with sarcomatoid dedifferentiation. Urol Oncol 33: 427.e17-23, 2015. PMID: 26004164. DOI: 10.1016/j.urolonc.2015.04.011

7 Shuch B, Said J, LaRochelle JC, Zhou Y, Li G,Klatte T, Pouliot F, Kabbinavar FF, Belldegrun AS and Pantuck AJ: Histologic evaluation of metastases in renal cell carcinoma with sarcomatoid transformation and its implications for systemic therapy. Cancer 116: 616-624, 2010. PMID: 19998348. DOI: $10.1002 /$ cncr. 24768

8 Moulton N, Devasahayam J, Kannuswamy R, Chandran A and Hofmann H: Rapidly metastasizing sarcomatoid renal cell carcinoma in a 76-year old male. Am J Case Rep 4: 221-223, 2016. DOI: $10.12691 /$ ajmcr-4-6-10

9 Fuser D, Hedberg ML, Dehner LP, Dehdashti F and Siegel BA: Extensive metastatic sarcomatoid renal cell carcinoma evaluated by $18 \mathrm{~F}-\mathrm{FDG}$ PET/CT: A case report and review of literature. J Kidney Cancer VHL 5: 1-6, 2018. PMID: 29354391. DOI: 10.15586/jkcvhl.2018.99

10 Liang X, Liu Y, Ran P, Tang M, Xu C and Zhu Y: Sarcomatoid renal cell carcinoma: A case report and literature review. BMC Nephrol 19: 84, 2018. PMID: 29636020. DOI: 10.1186/s12882018-0884-7

11 Wei S and Al-Saleem T: The pathology and molecular genetics of sarcomatoid renal cell carcinoma: A mini-review. J Kidney Cancer VHL 4: 19-23, 2017. DOI: PMID: 28725540. DOI: $10.15586 / \mathrm{jkcvhl} .2017 .70$

12 Culine S, Bekradda M, Terrier-Lacombe MJ and Droz JP: Treatment of sarcomatoid renal cell carcinoma: Is there a role for chemotherapy? Eur Urol 27: 138-141, 1995. PMID: 7744156. DOI: $10.1159 / 000475145$

13 Kwak C, Park YH, Jeong CW, Jeong H, Lee SE, Moon KC and $\mathrm{Ku} \mathrm{JH}$ : Sarcomatoid differentiation as a prognostic factor for immunotherapy in metastatic renal cell carcinoma. J Surg Oncol 95: 317-323, 2007. PMID: 17066434. DOI: 10.1002/jso.20669
$14 \mathrm{Yu}$ W, Wang Y, Jiang Y, Zhang W and Li Y: Distinct immunophenotypes and prognostic factors in renal cell carcinoma with sarcomatoid differentiation: A systematic study of 19 immunohistochemical markers in 42 cases. BMC Cancer 17: 293, 2017. PMID: 28449664. DOI: 10.1186/s12885-0173275-8

15 Varela I, Tarpey P, Raine K, Huang D, Ong CK, Stephens P, Davies H, Jones D, Lin ML, Teague J, Bignell G, Butler A, Cho J, Dalgliesh GL, Galappaththige D, Greenman C, Hardy C, Jia M, Latimer C, Lau KW, Marshall J, McLaren S, Menzies A, Mudie L, Stebbings L, Largaespada DA, Wessels LF, Richard S, Kahnoski RJ, Anema J, Tuveson DA, Perez-Mancera PA, Mustonen V, Fischer A, Adams DJ, Rust A, Chan-on W, Subimerb C, Dykema K, Furge K, Campbell PJ, Teh BT, Stratton MR and Futreal PA: Exome sequencing identifies frequent mutation of the SWI/SNF complex gene PBRM1 in renal carcinoma. Nature 469: 539-542, 2011. PMID: 21248752. DOI: $10.1038 /$ nature09639

16 da Costa WH, Rezende M, Carneiro FC, Rocha RM, da Cunha IW, Carraro DM, Guimaraes GC and de Cassio Zequi S: Polybromo-1 (PBRM1), a SWI/SNF complex subunit is a prognostic marker in clear-cell renal cell carcinoma. BJU Int 113: E157-163, 2014. PMID: 24053427. DOI: 10.1111/ bju. 12426

17 Wang K, Liu T, Liu L, Liu J, Wang C, Ge N, Ren H, Yan K, Hu $\mathrm{S}$, Björkholm M, Fan Y and Xu D: TERT promoter mutations in renal cell carcinomas and upper tract urothelial carcinomas. Oncotarget 5: 1829-1836, 2014. PMID: 24742867. DOI: 10.18632/oncotarget.1829

18 Bruder E, Passera O, Harms D, Leuschner I, Ladanyi M, Argani P, Argani P, Eble JN, Struckmann K, Schraml P and Moch H: Morphologic and molecular characterization of renal cell carcinoma in children and young adults. Am J Surg Pathol 28: 1117-1132, 2004. PMID: 15316311. DOI: 10.1097/01.pas.000 0131558.32412 .40

19 Yang K, Lindblad P, Egevad L and Hemmini K: Novel somatic mutations in the VHL gene in Swedish archived sporadic renal cell carcinomas. Cancer Lett 141: 1-8, 1999. PMID: 10454237. DOI: 10.1016/s0304-3835(99)00031-2

20 Cowey CL and Rathmell WK: VHL gene mutations in renal cell carcinoma: Role as a biomarker of disease outcome and drug efficacy. Curr Oncol Rep 11: 94-101, 2009. PMID: 19216840.

Received August 7, 2019

Revised September 9, 2019 Accepted September 19, 2019 